\title{
Macabéa secular
}

Claudia Nina*

Universidade de Utrecht

Resumo: Aproximação da trajetória de Macabéa, de $A$ hora da estrela, em sua mudez de palavra usurpada, e as escritoras brasileiras do século 19 na luta pela possibilidade de produção literária em um mundo todo feito contra elas, tal como este o foi para a personagem de Clarice Lispector.

Palavras-chave: Des-criação. Usurpada. Exílio. Liberdade.

Retroceder nos séculos para falar de um romance dos anos 1970 pode parecer uma viagem de anacronismo, mas não é. Insisto que a personagem em perspectiva me convida ao retrocesso; na verdade, náo convida: exige. Falo de uma protagonista em $3 \mathrm{D}$, que sai da página e de sua habitual mudez. Falo de Macabéa, que parece dizer entredentes:

- Fale de mim e de minha palavra usurpada.

Macabéa, todos conhecem de $A$ hora da estrela, usa aqui a expressão "difícil" porque gosta de palavras bonitas. Quem não se lembra? Ela repetia efemérides porque ouvira no rádio e saía repetindo em seus parcos diálogos com o mundo-namorado e o mundo da chefia no escritório. A expressão palavra usurpada obviamente não surgiu da rádio, mas é uma referência ao meu estudo traduzido no Brasil como A palavra usurpada: exílio e nomadismo na literatura de Clarice Lispector (Editora

* Jornalista, escritora, doutora em Letras.

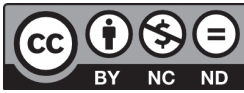

Esta obra está licenciada sob uma Licença Creative Commons. 
da PUC-RS), na qual analiso obras da autora de $A$ hora da estrela a partir da perspectiva de que algumas de suas personagens sáo tornadas silentes e indefesas diante de um narrador que lhes usurpa a palavra e o domínio da ação. Sem entrar em detalhes sobre a tese, tomo apenas emprestada a expressão para utilizá-la na observação de Macabéa em confronto com algumas autoras do século 19 , como se verá na sequência.

Proponho entrelaçar $A$ hora da estrela com a obra recente intitulada Encantaçóes: escritoras e imaginação literária no Brasil - século XIX, de Norma Telles, recentemente lançado pela Editora Intermeios. E por que este entrelace?

Sabe-se que Macabéa é a aquela personagem da qual fala um narrador que se declara, em uma confusa mistura de máscaras, um sujeito chamado Rodrigo SM, a majestade que toma para si o destino de uma mulher cujo rosto ele viu de relance nas ruas do Rio de Janeiro e, a partir desta imagem esfacelada, constrói uma mulher inteira, como autor de uma vida, tracejando a impiedosa caminhada da moça rumo à morte cruel no asfalto, não sem antes destituí-la da fala, da possibilidade de um amor e até de um passado decente. Macabéa é, portanto, aquela que não diz e que náo vive - a que pede desculpas por tentar existir em um mundo todo feito contra ela. A palavra usurpada; a vida usurpada. "Macabéa era na verdade uma figura medieval" (HE, p. 47). Retroceder aos séculos, muitos séculos para entendê-la.

Existe o direito ao grito, sim, como diz o narrador, mas apenas para Rodrigo e não para Macabéa, que silencia mesmo quando fala, porque suas palavras são toscas e não chegam a lugar algum, não criam diálogo capaz de transformar o outro. "As poucas conversas entre os namorados versavam sobre farinha, carne de sol, carne-seca, rapadura, melado.” (HE, p. 47); "Macabéa não passava de um vago sentimento nos paralelepípedos sujos". (HE, p. 83)

Macabéa secular, de palavra usurpada, conduz-nos ao século 19, especificamente no Brasil, quando e onde as mulheres não eram vistas como seres pensantes nem ao menos eram donas da própria imagem. Macabéa secular e sem palavras, criada por um narrador que se mascara de homem (seria na verdade Clarice Lispector, como antecipa o texto?) 188 
conduz-nos ao recanto das mulheres-escritoras brasileiras do século 19, aquelas que insistiam em, não apenas falar, mas ousaram escrever o pensamento, ainda que a duras penas.

Quanta ousadia e coragem precisavam ter para duelarem o monstro e os anjos que insistiam em rondar espelhos, lares e almas é o que revela a pesquisa de Norma Telles. É certo que muito já se falou sobre o assunto, que o diga Virginia Woolf. O que se deseja aqui é imbricar o drama destas mulheres aventureiras da escrita, tais como Narcisa Amália de Campos, Maria Benedicta Bormann e Júlia Lopes de Almeida, Maria Firmina dos Reis, Josefina Álvares de Azevedo, Gilka Machado, Auta de Souza, entre outras, e a desventurada Macabéa. Se Macabéa tivesse tido coragem de escrever a sua história, como seria? Se $A$ hora da estrela fosse narrado em uma brutal e convicta primeira pessoa, como teriam sido os passos da nordestina?

A condição geral das mulheres e, obviamente, das mulheresescritoras do século 19 era a da falta absoluta de liberdade para explorar os caminhos da mente. Eram excluídas em potencial: da sociedade, dos poderes políticos, da hierarquia na casa, onde ocupavam quase sempre a posição de comandadas. Muitas recorreram à linguagem da poesia e do sonho. Outras ao suicídio; inúmeras adoeceram - histeria, amnésia, afasia, loucura. Macabéa secular morreu sob as rodas de um Mercedes, e nem que tentasse encontrar refúgio nas letras não conseguiria: era datilógrafa de míseros recursos: "Por ser ignorante era obrigada na datilografia a copiar lentamente letra por letra - a tia é que lhe dera um curso ralo de como bater à máquina." (HE, p. 15)

A pesquisa de Norma Telles aponta a obra intitulada Úrsula, de Maria Firmina dos Reis, de 1859, como o primeiro romance escrito por uma mulher no Brasil. O tema: a questão dos escravos; a mulher-protagonista sofre horrores e morre enlouquecida. As mulheres, em qualquer situação ou cenário, mesmo sem serem, de fato, escravizadas, eram escravas de alguma forma... Macabéa, escrava social, miserável e faminta.

A autora em sua pesquisa ressalta a imensa dificuldade por parte das escritoras de tocar em assuntos acerca da emancipação ou da política - eram quase apedrejadas quando tentavam. Ela cita a poeta Narcisa 
Amália, que escreveu sobre as questóes femininas em $O$ Garatuja, de 1889. Narcisa é também autora de Nebulosas, de 1872, que esboça temas românticos. Tinha 20 anos e já estava separada do primeiro marido. O segundo casamento também acabou. Narcisa teve fama nacional, mas foi criticada nas décadas que se seguiram. Lutou, tentou viver como jornalista, tradutora e professora primária. Não conseguiu sustentar-se sozinha. Ela morreu cega e paralítica em 1924.

Autoras como Narcisa expuseram inevitavelmente a fragilidade de quem não fora treinada na vida para ter uma linguagem própria, ou seja, uma expressão peculiar e dominante diante do mundo. Não podendo agir com liberdade, náo podiam falar com liberdade e, por conseguinte, a escrita era quase sempre alguma coisa clandestina, que existia às custas de muito esforço contra o poderio masculino, incluindo aí a descrença e a indiferença que inspiravam nos outros e que as empurravam quase inevitavelmente para o anonimato, a loucura ou a morte.

A pesquisa de Norma Telles cita também Maria Benedicta Borgmann (ou Bormann, na grafia mais comumente usada), que foi autora, entre outros, de Lésbia, ficçáo em torno do que seria a vida de uma escritora no Rio de Janeiro no final do século 19. Bormann teve uma carreira de 10 anos (romances, contos e folhetins em jornais) até a morte prematura, em 1895. A personagem de Lésbia é uma mulher que não desanima diante das adversidades, e se inspira em George Sand. Curioso como os temas se repetem sem muita originalidade, isso porque expressam/espelham as próprias lutas internas contra uma situação de domínio.

Interessante observar como se realiza a luta interna de Macabéa que é desrealizada na vida do texto a partir do momento em que não é construída pelo narrador, mas sim desconstruída. Rodrigo SM faz a moça desmoronarse em nojo, asco, inutilidade diante dos leitores, que, no máximo, são estimulados a sentir pena, compaixáo em relaçáo a um ser tấo nulo, à toa, com fome e dor de dentes, raquítica, sem destino e sem amor. E o que vale a escrita neste jogo de desconstruçấo? Muito pouco, porque o narrador, segundo ele mesmo, vive de fracasso em fracasso. (HE, p. 18).

É rica e complexa esta filosófica articulação entre a criação (descriação?) de uma personagem em direção à morte e, simultaneamente, 190 
em uma mesma obra, a reflexão sobre literatura em oposição à vida, como se arte e realidade fosse excludentes, ou um justificasse o outro. Questiona-se, neste embate entre escritor e personagem, a própria essência da literatura e para o que serve, afinal, essa arte das palavras e do pensamento da qual foram destituídas não só Macabéa, por ser uma pobre datilógrafa que não entendia a existência do encontro entre duas consoantes, como muitas mulheres que nem ousaram afugentar os monstros da casa que as aprisionavam na vida comum, medíocre e sem expressão, para uma folha de papel em branco.

Os papéis que Macabéa tocava eram tornados sujos pelas suas mãos inábeis que borravam documentos com tinta de máquina; Macabéa não escrevia, nem pensava: ela borrava. A metáfora das palavras borradas é, de fato, irrecusável. A protagonista é a não-protagonista por excelência, já que não é capaz de gerir seu próprio discurso, de criar um texto sem borróes...

$\mathrm{Na}$ contramão do fracasso, um nome importante (e de sucesso) citado por Norma Telles em sua pesquisa é o de Júlia Lopes de Almeida, que escrevia desde menina - escondida. A sorte foi que, ao contrário das expectativas, quando o pai descobriu, em vez de puni-la, resolveu facilitar o ingresso da filha no jornalismo. Júlia começava a ter ali um destino bem diferente do de Macabéa e de tantas outras náo-protagonistas da palavra, do texto e da vida.

Ela começou a escrever profissionalmente na Gazeta de Campinas, em 1885. Escreveu contos e romances, como A família Medeiros, A viúva Simóes e $A$ falência. Entre as escritoras, Júlia foi uma das que melhor conseguiu fama e respeito nacional. Ganhou dinheiro com a profissão, sua carreira se estendeu por longos 40 anos. Firmou a imagem da mulher capaz de vencer sem abrir mão de nada do que acreditava. Encontrou sua imagem em um espelho sem fantasmas. No espelho onde Macabéa (mal) se observa surge a figura de Rodrigo SM. A mulher não tem direito sequer à própria imagem - "Vejo a nordestina se olhando ao espelho e - um ruflar de tambor - no espelho aparece o meu rosto cansado e barbudo" (HE, p. 22).

A aproximação entre uma novela de 1977 e uma pesquisa sobre mulheres escritoras do século 19 me acendeu uma ideia: a de recriar 
Macabéa, facultando-lhe o direito ao grito. Como seria a história se assim pudesse ser? Como reescrever um texto de forma a realizar uma protagonista em vez de des-criá-la? Eis alguns desafios do contemporâneo para refazer os passos estelares desta secular heroína do asfalto.

[Texto recebido em maio de 2013 para compor a corrente edição especial]

\section{Referências}

LISPECTOR, Clarice. A hora da estrela. Rio de Janeiro: Rocco, 1998.

NINA, Claudia. A palavra usurpada: itinerários exílico-nomádicos na literatura de Clarice Lispector. Porto Alegre: EdiPUC-RS.

TELLES, Norma. Encantaçôes: escritoras e imaginação literária no Brasil - século XIX. São Paulo: Intermeios, 2012.

\section{Secular Macabéa}

Abstract: Approaching Macabéa's trajectory, from $A$ hora da estrela, in his muteness misused word, and Brazilian women writers of the 19th century in the struggle for the possibility of literary production in a world made against them, as this was to the character of Clarice Lispector.

Keywords: Des-creation. Misused. Exile. Freedom.

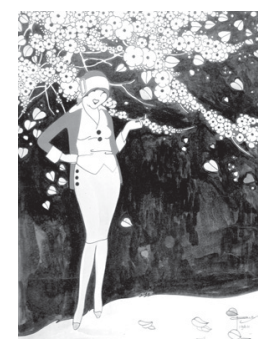

